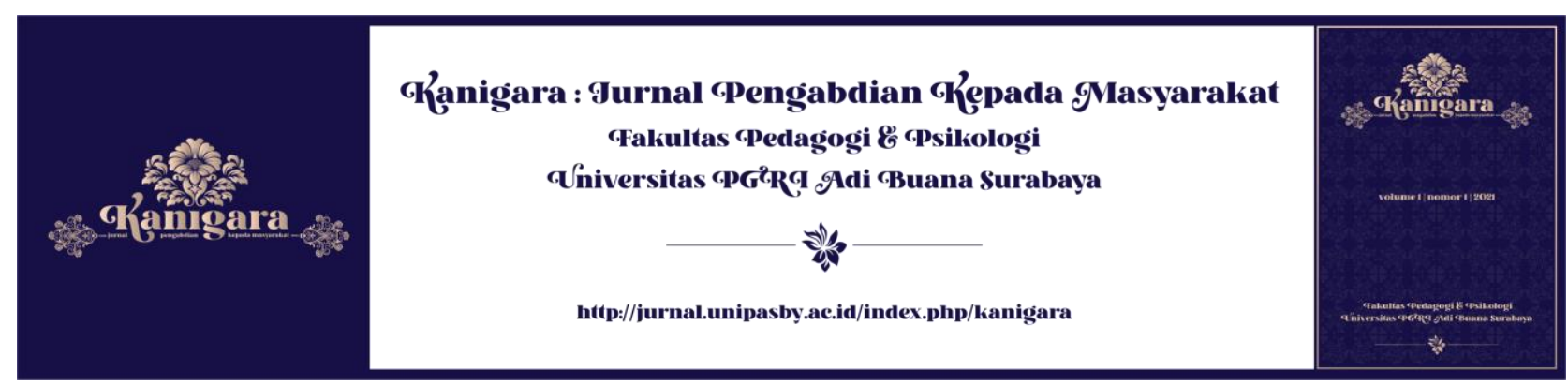

\title{
PEMANFAATAN VIDEOSCRIBE DALAM PENINGKATAN KOMPETENSI GURU
}

\author{
Tri Astuti Arigiyati ${ }^{1}$, Betty Kusumaningrum ${ }^{2}$, Krida Singgih Kuncoro ${ }^{3 *}$ \\ 1,2,3 Prodi Pendidikan Matematika, Universitas Sarjanawiyata Tamansiswa, Yogyakarta \\ *Email: krida.kuncoro@ustjogja.ac.id
}

\begin{tabular}{l}
\hline Informasi Artikel \\
Kata kunci: \\
media pembelajaran, \\
VideoScribe, kompetesi \\
guru
\end{tabular}

Diterima: 12-01-2021

Disetujui: 20-01-2021

Dipubikasikan: 25-012021

\begin{abstract}
Abstrak
Media pembelajaran yang digunakan guru masih tergolong sederhana, seperti LKS dan buku siswa yang diterbitkan Kemendikbud serta PowerPoint dan video pembelajaran yang sudah ada di YouTube. Belum ditemukan guru yang menggunakan VideoScribe, dan multimedia berbasis PowerPoint. Mayoritas PowerPoint hanya digunakan sebagai media presentasi dengan fitur-fitur yang sederhana. Pembelajaran dengan media yang biasa digunakan guru masih belum terlalu menarik perhatian siswa. Siswa beranggapan bahwa media pembelajaran yang digunakan guru tidak ada hal baru yang membuat siswa tertarik untuk memahami materi pelajaran. Dampak yang terjadi adalah kurangnya minat, motivasi dan antusiasme siswa dalam mengikuti pembelajaran, akibatnya prestasi belajar siswa masih di bawah KKM. Solusi permasalahan yang ditawarkan terkait dengan permasalahan yang ada adalah dilaksanakannya kegiatan pelatihan dan pendampingan pengembangan media pembelajaran berbasis Sparkol VideoScribe bagi guru SMP Muhammadiyah 4 Yogyakarta. Keefektifan pelatihan ini diukur dengan angket keefektifan dan jumlah guru yang mampu menggunakan VideoScribe.
\end{abstract}

Abstact
The learning media used by teachers are still relatively simple, such as
student worksheets and student books published by the Ministry of
Education and Culture and PowerPoint and learning videos that are already
on YouTube. Not yet found a teacher who uses VideoScribe and PowerPoint-
based multimedia. The majority of PowerPoints are only used as a media
presentation with simple features. Learning with the media used by teachers
is still not too exciting for students' attention. Students assume that the
learning media used by teachers have nothing new that makes students
interested in understanding the subject matter. The impact that occurs is the
lack of interest, motivation, and enthusiasm of students in participating in
learning; consequently, student learning achievement is still below the KKM.
The solution to the problem offered is related to the existing problem is the
implementation of training activities and mentoring the development of
learning media based on Sparkol VideoScribe for Muhammadiyah 4
Yogyakarta Middle School teachers. The effectiveness of this training was
measured by the effectiveness questionnaire and the number of teachers who
can use VideoScribe.




\section{PENDAHULUAN}

Penerapan teknologi pada era 4.0 ini menjadi sebuah keniscayaan mengingat segala aspek kehidupan telah menggunakan teknologi sebagai sarana mempermudah dalam melakukan sesuatu, termasuk dalam bidang pendidikan (Daud, Aulia, \& Ramayanti, 2019; Putrawangsa \& Hasanah, 2018). Seiring perkembangan kurikulum yang semakin dinamis ini, teknologi mempunyai peranan yang sangat penting untuk menunjang proses pembelajaran (Hegedus \& Moreno-Armella, 2020). Renstra Depdiknas 2005-2009 menyatakan peranan strategis TIK, untuk pilar pertama adalah perluasan dan pemerataan akses pendidikan, diprioritaskan sebagai media pembelajaran jarak jauh. Sedangkan untuk pilar kedua, peningkatan mutu, relevansi dan daya saing, peran TIK diprioritaskan untuk penerapan dalam pendidikan/proses pembelajaran. Terakhir, untuk penguatan tata kelola, akuntabilitas dan citra publik, peran TIK diprioritaskan untuk sistem informasi manajemen secara terintegrasi (Parwati, 2019).

Pemanfaatan teknologi dalam pembelajaran sangat dianjurkan bagi guru dalam rangka melaksanakan kurikulum 2013 (Krisdiana, Apriandi, \& Setiansyah, 2014). Dalam kurikulum 2013, TIK bukan sebagai mata pelajaran khusus akan tetapi mengintegrasikan TIK dalam setiap proses pembelajarannya (Irfan, 2015; Riyana, 2007). Oleh karena itu, diharapkan bahwa semua guru mata pelajaran apa pun mampu menguasai dan menggunakan teknologi saat melakukan pembelajaran. Teknologi berperan sangat penting sebagai sarana menyampaikan informasi kepada siswa (Chevallard \& Bosch, 2020). Dengan adanya pemanfaatan teknologi konsep yang sulit dapat disajikan dengan menarik dan menyenangkan sehingga menjadi mudah dipahami oleh siswa (Purba et al., 2020).

Media pembelajaran yang digunakan dalam proses pembelajaran di SMP Muhammadiyah 4 masih menggunakan media pembelajaran biasa seperti LKS dan buku siswa yang diterbitkan Kemendikbud serta PowerPoint dan video pembelajaran yang sudah ada di YouTube. Dari hasil pengamatan belum ditemukan guru yang menggunakan media pembelajaran serupa VideoScribe. Mayoritas PowerPoint hanya digunakan sebagai media presentasi dengan fitur-fitur yang sederhana. Dari media pembelajaran yang biasa digunakan guru diperoleh respon siswa yang kurang tertarik untuk mengikuti pembelajaran.

Berdasarkan hasil wawancara dengan siswa SMP Muhammadiyah 4 Yogyakarta, didapatkan bahwa siswa beranggapan bahwa media pembelajaran yang digunakan guru sudah biasa mereka lihat sehingga tidak ada hal baru yang membuat siswa tertarik untuk memperhatikan guru menjelaskan pelajaran. Selain itu, siswa juga beranggapan bahwa media yang biasa digunakan guru kurang mengikuti selera siswa seperti kurangnya warna-warni serta tidak bervariasi karena biasanya hanya menggunakan PowerPoint saja. Hal ini dikuatkan dengan hasil wawancara dengan guru SMP Muhammadiyah 4 bahwa guru belum mengenal 
software VideoScribe, sehingga belum pernah membuat media pembelajaran berbasis media tersebut. Padahal dengan pemanfaatan teknologi informasi dalam pembelajaran dapat meningkatkan efektivitas dalam pelaksanaan proses pembelajaran yang pada akhirnya diharapkan dapat meningkatkan hasil belajar siswa serta mutu individu para peserta didik dalam hal penggunaan teknologi secara lebih tepat dan bermanfaat (Husain, 2014).

Kendala-kendala dalam pembelajaran seperti kesalahan penyampaian maupun sulitnya menggunakan media nyata seharusnya dapat diminimalisir dengan teknologi yang semakin lama semakin berkembang serta dapat memunculkan ide baru yang dapat diadopsi sebagai bahan untuk membuat media pembelajaran yang baik dan menarik. Salah satunya adalah dengan menggunakan software Sparkol VideoScribe dan multimedia interaktif dengan PowerPoint dengan bantuan fitur trigger dan script. Collins et al (Asyhar, 2011) menunjukkan bahwa penggunaan media audio dan video berpengaruh terhadap hasil belajar peserta didik.

Sparkol VideoScribe adalah sebuah media presentasi dengan efek presentasi yang lebih menarik, lebih terkesan baru dan berbeda dari media presentasi lain yang biasa digunakan guru. Pada VideoScribe dapat dimasukkan suara berupa suara rekaman ataupun musik yang sudah jadi, serta dapat pula dimasukkan gambar animasi yang dapat menjadi ilustrasi dalam pembelajaran. Dengan adanya efek presentasi yang unik dan baru dirasa dapat membuat siswa tertarik untuk memperhatikan pembelajaran dengan menggunakan Sparkol VideoScribe. Dengan menggunakan software ini, kita dapat membuat tampilan media pembelajaran yang sangat menarik serta penyampaian yang tidak membosankan. VideoScribe menghasilkan media berupa video yang bisa dimanfaatkan sebagai media pembelajaran.

Software ini memungkinkan pengguna membuat whiteboard animation atau animasi papan putih seperti halnya kita menulis di atas papan tulis yang berwarna putih. Akan tetapi dengan menggunakan software ini kita dapat membuat tampilan seperti pada papan tulis di dalam komputer dengan penambahan gambar atau animasi lain sehingga menjadi tampilan media pembelajaran yang sangat menarik. Software ini dapat membantu guru dalam menjelaskan materi kepada siswa secara efektif karena penyampaian materi di desain secara rapi sebelum masuk ke dalam kelas sehingga dapat mengurangi kesulitan-kesulitan dan kendala dalam menjelaskan.

Menurut (Rusman, Kurniawan, \& Riyana, 2011) televisi, film, foto, rekaman audio, video, gambar yang diproyeksikan, bahan-bahan cetakan, dan sejenisnya adalah media komunikasi. Apabila media tersebut membawa pesan-pesan atau informasi yang bertujuan instruksional atau mengandung maksud-maksud pengajaran, maka media tersebut disebut media pembelajaran. Media pembelajaran mencakup semua sumber yang diperlukan untuk melakukan komunikasi dalam pembelajaran, sehingga bentuknya bisa berupa perangkat keras (hardware), seperti komputer, proyektor, televisi, dan perangkat lunak (software) yang 
Pemanfaatan VideoScribe dalam Peningkatan Kompetensi Guru

digunakan pada perangkat keras itu (Kwartolo, 2010).

(Rusman et al., 2011) juga menyatakan bahwa proses pembelajaran dapat berhasil dengan baik apabila siswa diajak untuk memanfaatkan semua alat indranya. Semakin banyak alat indra yang digunakan untuk menerima dan mengolah informasi semakin besar kemungkinan informasi tersebut dimengerti dan dipahami serta dapat dipertahankan dalam ingatan. Hal ini sejalan dengan konsep 3N (Niteni, Nirokke, Nambahi) yang dikenalkan pertama kali oleh Ki Hadjar Dewantara. Menurut Ki Hadjar Dewantara, dalam proses belajar siswa harus mengimplementasikan potensi dengan cara "niteni", "nirokke", dan "nambahi" (Rahayu, Purnami, \& Agustito, 2018; Wigati, Rahmawati, \& Widodo, 2018). Niteni adalah upaya mencari kejelasan dari suatu peristiwa atau keadaan melalui pengamatan secara jeli dan mendalam. Nirokke adalah aktivitas menirukan dari apa yang dilihat, didengar, dirasakan dalam bentuk contoh atau teladan yang baik. Sedangkan Nambahi adalah suatu aktivitas melengkapi melalui inovasi dan kreativitas sehingga menimbulkan hal-hal yang baru. Konsep niteni, nirokke, dan nambahi dalam implementasinya bukan merupakan hal yang dapat dipisahkan antara satu dengan yang lainnya. Satu hal tidak meninggalkan hal yang lain. Melainkan ketiganya integral dalam satu aktivitas sehingga menghasilkan pengetahuan dan keterampilan yang utuh.

Menurut konsep 3N ini, siswa harus menggunakan semua indranya agar kemampuan niteni, nirokke, nambahi yang memang sejatinya sudah ada dalam diri siswa dapat digunakan seoptimal mungkin. Pertama dalam hal Niteni, siswa harus menggunakan indra penglihatan dan pendengaran dengan baik agar upaya pengamatan secara mendalam dapat mencapai hasil maksimal. Kedua dalam hal Nirokke, Nirokke merupakan aktivitas menirukan, sehingga indra yang terlibat di sini adalah indra penglihatan, pendengaran, pengecap dan peraba. Aktivitas menirukan bisa berarti menirukan dengan suara, menirukan dengan tulisan, atau bisa juga menirukan dengan gerakan. Kemudian ketiga, dalam hal Nambahi, siswa harus berkreasi menambahkan, menciptakan sesuatu yang baru. Semua indra harus digunakan untuk menciptakan sesuatu yang baru ini. Oleh karena itu, pemanfaatan media pembelajaran diharapkan dapat meningkatkan kemampuan Niteni, Nirokke, Nambahi dalam diri siswa, sehingga proses pembelajaran berjalan dengan optimal dan mendapatkan kualitas pembelajaran yang maksimal.

Program Kemitraan Masyarakat ini menjalin kerja sama dengan Kepala Sekolah SMP Muhammadiyah 4 Yogyakarta merupakan upaya untuk menyelesaikan masalah yang terjadi di sekolah tersebut yakni dengan pelatihan dan pendampingan pengembangan media pembelajaran berbasis Sparkol VideoScribe agar siswa dapat meningkatkan kemampuan Niteni, Nirokke, Nambahi sesuai dengan ajaran Tamansiswa yang disampaikan oleh Ki Hadjar Dewantara. 


\section{METODE}

Pelaksanaan kegiatan pengabdian kepada masyarakat ini dilakukan oleh tim dosen dan mahasiswa jurusan pendidikan matematika, FKIP Universitas Sarjanawiyata Tamansiswa Yogyakarta pada hari Kamis tanggal 15 Agustus 2019 pukul 08.00-16.00 WIB di SMP Muhammadiyah 4 Yogyakarta. Metode yang digunakan adalah dengan melakukan sosialisasi, pelatihan, dan pendampingan bagi guru SMP Muhammadiyah 4 Yogyakarta. Tahapan pelaksanaan kegiatan pengabdian kepada masyarakat dapat dilihat pada Gambar 1.

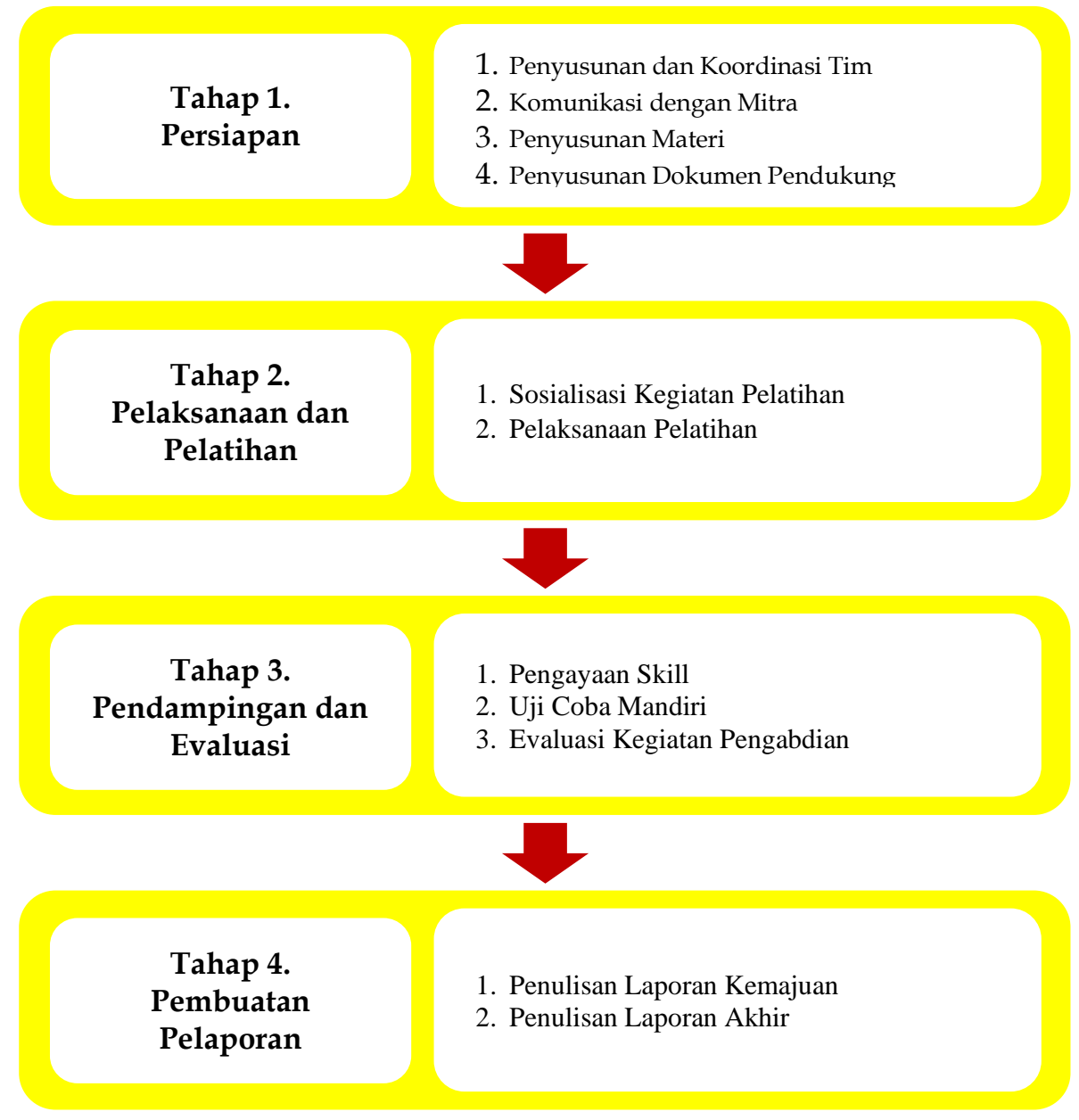

Gambar 1. Tahapan Pelaksanaan Kegiatan Pengabdian kepada Masyarakat

Pada tahap 1 (tahap persiapan) ini tim abdimas berkoordinasi untuk melakukan observasi awal dan berkomunikasi dengan sekolah mitra mengenai kesulitan yang dihadapi. Kemudian tim menyusun materi abdimas dan mempersiapkan dokumen-dokumen pendukung seperti surat ijin, surat permohonan, surat tugas, dan presensi. Pada tahap 2 (pelaksanaan dan pelatihan) ini tim melakukan sosialisasi mengenai kegiatan pelatihan dan melaksanakan kegiatan pelatihan yang telah disepakati bersama. Pada tahap 3 (pendampingan dan evaluasi) ini tim melakukan kegiatan pendampingan bagi guru dalam pembuatan media pembelajaran berbasis VideoScribe. Guru membuat media pembelajaran sesuai dengan mata pelajaran yang diampu sehingga guru lebih mudah mengaplikasikannya apa yang akan disampaikan dalam media pembelajaran. Setelah pendampingan selesai, tim 
abdimas mengadakan evaluasi dengan memberikan angket keterlaksanaan program abdimas dan mereviu media pembelajaran yang telah dibuat oleh guru. Pada tahap 4 (tahap pembuatan pelaporan), Tim berkoordinasi untuk menyusun laporan akhir kegiatan abdimas dan melakukan persiapan publikasi ilmiah.

Pada tahap persiapan, selain penyusunan dan koordinasi serta komunikasi dengan mitra, kegiatan yang dilakukan lainnya adalah membuat materi. Materi pelatihan yang disampaikan saat kegiatan pengabdian kepada masyarakat disajikan dalam Tabel 1.

Tabel 1. Materi Pelatihan

\begin{tabular}{cc}
\hline PROGRAM & \multicolumn{1}{c}{ MATERI PELATIHAN } \\
\hline Sosialisasi & $\begin{array}{l}\text { Sosialisasi pentingnya pemanfaatan Tekonologi Informasi } \\
\text { dalam proses pembelajaran dan kaitannya dengan } \\
\text { implementasi ajaran Tamansiswa }\end{array}$ \\
\cline { 2 - 2 } & $\begin{array}{l}\text { Pengenalan Software Sparkol VideoScribe dan PowerPoint } \\
\text { berbasis script \& trigger sebagai salah satu alternatif untuk } \\
\text { mengembangkan media yang atraktif dan interaktif }\end{array}$ \\
\hline Pelatihan & $\begin{array}{l}\text { 1. Cara mendownload software Sparkol VideoScribe } \\
\text { 2. Cara menggunakan menu yang tersedia pada software dan } \\
\text { trigger/script pada PowerPoint }\end{array}$ \\
& $\begin{array}{l}\text { 3. Cara mengoperasikan software Sparkol VideoScribe dan } \\
\text { trigger/script pada PowerPoint untuk membuat media } \\
\text { pembelajaran }\end{array}$ \\
\hline Pendampingan & $\begin{array}{l}\text { Pendampingan kepada guru sampai media pembelajaran } \\
\text { siap digunakan dalam pembelajaran }\end{array}$ \\
\hline Evaluasi & Evaluasi kegiatan dan refleksi bersama dengan guru \\
\hline
\end{tabular}

\section{HASIL DAN PEMBAHASAN}

Kegiatan pengabdian ini dilakukan sebagai upaya mengatasi permasalahan yang ditemukan di lapangan yaitu belum digunakannya VideoScribe sebagai media pembelajaran yang dapat meningkatkan efektivitas proses pembelajaran yang pada akhirnya diharapkan dapat meningkatkan hasil belajar siswa. Media pembelajaran yang digunakan dalam proses pembelajaran di SMP Muhammadiyah 4 masih menggunakan media pembelajaran biasa seperti LKS dan buku siswa yang diterbitkan Kemendikbud serta PowerPoint dan video pembelajaran yang sudah ada di YouTube.

Solusi permasalahan yang ditawarkan adalah dengan memberikan pelatihan dan pendampingan pengembangan media pembelajaran berbasis Sparkol VideoScribe bagi guru SMP Muhammadiyah 4 Yogyakarta. Tahapan pelatihan tersebut adalah dengan mengadakan sosialisasi terlebih dahulu akan pentingnya pemanfaatan teknologi dalam proses pembelajaran untuk meningkatkan motivasi siswa, kemudian memberikan pelatihan pembuatan media pembelajaran berbasis Sparkol VideoScribe, dan yang terakhir adalah pendampingan pembuatan media pembelajaran. 
Kegiatan sosialisasi yang diadakan adalah sosialisasi akan pentingnya pemanfaatan teknologi informasi dalam proses pembelajaran dan kaitannya dengan implementasi ajaran Tamansiswa, dan pengenalan Software Sparkol VideoScribe sebagai salah satu alternatif untuk mengembangkan media yang atraktif dan interaktif. Setelah kegiatan sosialisasi, kegiatan berikutnya adalah pelatihan meliputi cara men-download software Sparkol VideoScribe, cara menggunakan menu yang tersedia pada software dan cara mengoperasikan software Sparkol VideoScribe untuk membuat media pembelajaran. Kegiatan yang terakhir adalah pendampingan kepada guru hingga media pembelajaran siap digunakan dalam pembelajaran.

Pada tahap ini, guru terlihat sangat antusias dalam membuat media pembelajaran dengan software Sparkol VideoScribe. Hal ini ditunjukkan dengan hampir semua guru yang mengikuti pelatihan mengumpulkan file Sparkol VideoScribe kepada Tim. Berikut beberapa hasil media yang dibuat oleh guru menggunakan Sparkol VideoScribe.

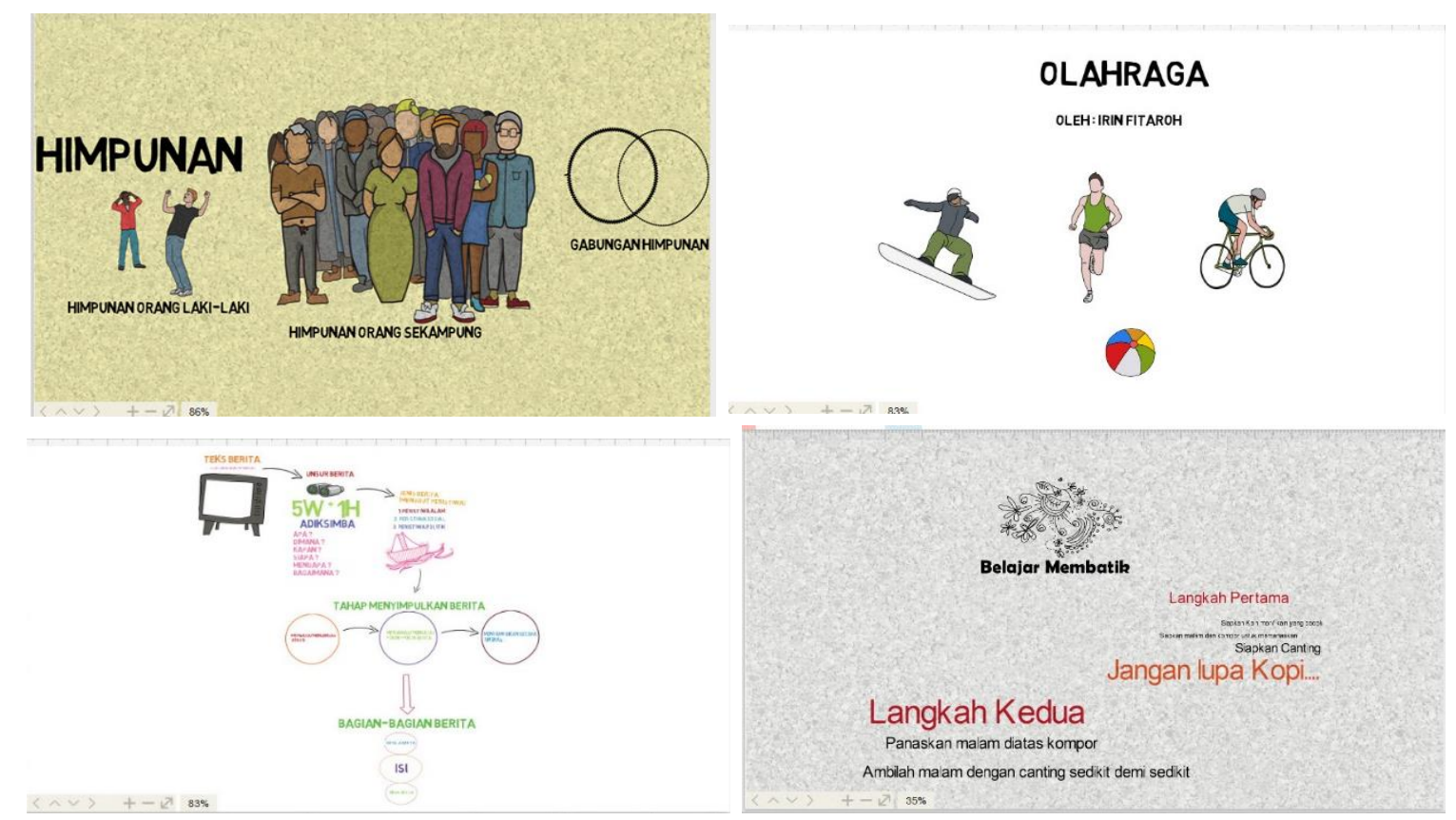

Gambar 2. Tampilan video yang dibuat oleh guru pada saat pelatihan Sparkol VideoScribe.

Setelah rangkaian kegiatan pengabdian selesai, guru-guru SMP Muhammadiyah 4 kemudian diminta untuk mengisi kuesioner mengenai keterlaksanaan kegiatan pengabdian. Evaluasi kegiatan pengabdian meliputi kesesuaian materi yang disampaikan dengan tujuan kegiatan, kejelasan penyampaian materi, kecukupan waktu yang digunakan, kebermanfaatan materi yang diberikan, materi yang mudah dimengerti, dan keberlanjutan peserta menerapkan materi dalam pembelajaran. Dari hasil kuesioner, diperoleh rata-rata nilai total sebesar 3,72 sehingga dapat dikatakan bahwa kegiatan pengabdian kepada masyarakat ini terlaksana dengan sangat baik.

Sejalan dengan hasil pengabdian yang dilakukan oleh Astuti, Sumarni, \& Bhakti, (2019), 
hasil video saat setelah pelatihan Sparkol VideoScribe dapat digunakan sebagai bahan pembelajaran dikelas dalam proses kegiatan belajar mengajar. Media pembelajaran menggunakan Sparkol VideoScribe ini diharapkan dapat dijadikan inovasi dalam pembelajaran yang dapat lebih menarik minat siswa untuk lebih rajin dalam belajar.

\section{KESIMPULAN}

Guru di sekolah mitra belum menggunakan VideoScribe sebagai media pembelajaran karena sebagian besar guru baru mengenal VideoScribe sedangkan beberapa guru lain sudah mengenal namun belum mendalami VideoScribe sebagai inovasi dalam pembelajaran. Setelah mendapat pelatihan, sebagian besar guru mengatakan bahwa mereka mendapat tambahan pengetahuan tentang apa itu VideoScribe dan penggunaannya dalam pembelajaran. Para guru juga mendapat tambahan keterampilan dengan langsung dapat membuat media pembelajaran menggunakan VideoScribe sesuai dengan mata pelajaran yang diampu oleh masing-masing guru.

Secara umum kegiatan ini berjalan dengan lancar dan tertib, peserta pelatihan juga antusias dalam memahami materi yang diberikan. Antuasime peserta pelatihan ditunjukkan dengan banyaknya peserta yang mengajukan pertanyaan seputar materi yang diberikan, dan keseriusan peserta dalam membuat materi pembelajaran menggunakan media berbasis Sparkol VideoScribe. Kegiatan pelatihan dinilai efektif karena berdasarkan hasil kuesioner, tingkat keterlaksanaan kegiatan pengabdian cukup tinggi. Selain itu, berdasarkan hasil kegiatan, dapat disimpulkan bahwa kegiatan pengabdian ini telah mencapai tujuan yang diharapkan yaitu lebih dari 90\% guru bisa membuat media pembelajaran sesuai dengan mata pelajaran yang diampu menggunakan VideoScribe.

\section{UCAPAN TERIMA KASIH}

Penulis mengucapkan terima kasih kepada Universitas Sarjanawiyata Tamansiswa melalui Lembaga Penelitian, Pengembangan, dan Pengabdian kepada Masyarakat (LP3M) yang telah mendanai program ini dan SMP Muhammadiyah 4 Yogyakarta yang telah mendukung kegiatan ini. 


\section{DAFTAR PUSTAKA}

Astuti, I. A. D., Sumarni, R. A., \& Bhakti, Y. B. (2019). Pengembangan Multimedia Interaktif Berbasis Lectora Inspire sebagai Media Pembelajaran Guru. Abdimas Dewantara, 2(2), 107-114. https:// doi.org/http:/ / dx.doi.org/10.30738/ad.v2i2.2872

Asyhar, R. (2011). Kreatif Mengembangkan Media Pembelajaran (Jakarta. Jakarta: Gaung Persada Press.

Chevallard, Y., \& Bosch, M. (2020). Didactic transposition in mathematics education. Encyclopedia of Mathematics 214-218. https://doi.org/https://doi.org/10.1007/978-3-030-15789-0_48

Daud, A., Aulia, A. F., \& Ramayanti, N. (2019). Integrasi teknologi dalam pembelajaran: Upaya untuk beradaptasi dengan tantangan era digital dan revolusi industri 4.0. Unri Conference Series: Community Engagement, 1, 449-455. https://doi.org/https://doi.org/10.31258/unricsce.1.449-455

Hegedus, S., \& Moreno-Armella, L. (2020). Information and communication technology (ICT) affordances in mathematics education. Encyclopedia of Mathematics Education, 380-384. https://doi.org/https://doi.org/10.1007/978-3-030-15789-0_78

Husain, C. (2014). Pemanfaatan teknologi informasi dan komunikasi dalam pembelajaran di SMA Muhammadiyah Tarakan. Jurnal Kebijakan Dan Pengembangan Pendidikan, 2(2). https://doi.org/https:// doi.org/10.22219/jkpp.v2i2.1917

Irfan, M. (2015). Pengaruh Kompetensi Teknologi Informasi dan Komunikasi (TIK) Guru Terhadap Pelaksanaan Kurikulum 2013 di Sekolah Dasar Negeri Kota Banjarbaru. STIE Indonesia Banjarmasin.

Krisdiana, I., Apriandi, D., \& Setiansyah, R. K. (2014). Analisis Kesulitan yang Dihadapi oleh Guru dan Peserta Didik Sekolah Menengah Pertama dalam Implementasi Kurikulum 2013 pada Mata Pelajaran Matematika (Studi Kasus Eks-Karesidenan Madiun). JIPM (Jurnal Ilmiah Pendidikan Matematika), https://doi.org/http://doi.org/10.25273/jipm.v3i1.492

Kwartolo, Y. (2010). Teknologi informasi dan komunikasi dalam proses pembelajaran. Jurnal Pendidikan Penabur, 14, 15-43.

Parwati, N. N. (2019). Adaptasi Pembelajaran Matematika di Era Revolusi Industri 4.0. Prosiding SENAMA PGRI, 1, 1-11.

Purba, R. A., Tamrin, A. F., Bachtiar, E., Makbul, R., Rofiki, I., Metanfanuan, T., ... Irawan, E. (2020). Teknologi Pendidikan. Yayasan Kita Menulis.

Putrawangsa, S., \& Hasanah, U. (2018). Integrasi Teknologi Digital Dalam Pembelajaran Di $\begin{array}{lllll}\text { Era Industri } & \text { 4.0. Jurnal } & \text { T2-54. }\end{array}$ https://doi.org/https://doi.org/10.20414/jtq.v16i1.203

Rahayu, I., Purnami, A. S., \& Agustito, D. (2018). Penerapan Konsep 3N (Niteni, Nirokke, Nambahi) untuk Meningkatkan Motivasi Belajar Matematika Siswa. Prosiding Seminar Nasional Pendidikan Matematika Etnomatnesia.

Riyana, C. (2007). Pedoman pengembangan media video. Jakarta: P3ai Upi.

Rusman, Kurniawan, D., \& Riyana, C. (2011). Pembelajaran Berbasis Teknologi Informasi dan Komunikasi Mengembangkan Preofesionalitas Guru. Jakarta: PT Raja Grafindo Persada.

Wigati, S., Rahmawati, D. S., \& Widodo, S. A. (2018). Pengembangan Youtube Pembelajaran Berbasis Ki Hadjar Dewantara Untuk Materi Integral di SMA. Prosiding Seminar Nasional Pendidikan Matematika Etnomatnesia. 